\title{
Contribution of the Defective BRCA1, BRCA2 and CHEK2 Genes to the Familial Aggregation of Breast Cancer: a Simulation Study Based on the Swedish Family-Cancer Database
}

\author{
Justo Lorenzo Bermejo', Alfonso García Pérez², Kari Hemminki ${ }^{1,3}$ \\ 'Division of Molecular Genetic Epidemiology, German Cancer Research Centre (DKFZ), Heidelberg, Germany; ${ }^{2}$ Department of Statistics, Spanish Open University (UNED), \\ Madrid, Spain; ${ }^{3}$ Department of Biosciences at Novum, Karolinska Institute, Huddinge, Sweden
}

Key words: familial relative risk, $B R C A 1, B R C A 2, C H E K 2$, disease penetrance, demographic factors

Corresponding author: Justo Lorenzo Bermejo, Division of Molecular Genetic Epidemiology, German Cancer Research Centre (DKFZ), Im Neuenheimer Feld 580, D-69120, Heidelberg, Germany, e-mail: J.Lorenzo@dkfz.de

Submitted: 2 November 2004

Accepted: 10 November 2004

\begin{abstract}
The known breast cancer susceptibility genes only account for $20 \%$ to $25 \%$ of the excess familial risk of the disease [1]. The present study assessed the contribution of BRCA1/2 mutations and CHEK2 variants to the relative risk of breast cancer for women with affected mothers or sisters. The familial relative risks were estimated by Poisson regression based on the Swedish Family-Cancer Database. The Database was also used to calculate the distribution of life expectancy, the number of daughters per family and the age specific cumulative risk of female breast cancer. This information, together with the penetrances of BRCA1, BRCA2 and CHEK2 from the literature, was used to simulate the familial clustering of breast cancer under different scenarios. The excess risk explained by BRCA1, BRCA2 and CHEK2 decreased steeply with the age at diagnosis of the cancers. Around $40 \%$ of the familial risk for cases diagnosed before the age of 50 years was associated with BRCA1/2 mutations. In contrast, roughly $85 \%$ of the familial risk of breast cancer diagnosed before the age of 69 years remained unexplained. The contribution of CHEK2 to familial breast cancer was small.
\end{abstract}

\section{Introduction}

Breast cancer aggregates in families, the disease being about twice as common in mothers and sisters of cases as it is in the general population [2]. The higher risks of breast cancer for monozygotic than for dizygotic twins of cases suggest that the familial aggregation of breast cancer is mainly due to genetic effects, rather than to shared environmental factors [3]. Germline mutations in BRCA1 and BRCA2 are frequently found in families containing multiple individuals affected by breast cancer [4]. However,
$B R C A 1$ and BRCA2 mutations are only identified in about $15-20 \%$ of multiple-case families affected by breast cancer alone [5]. CHEK2*1100delC, a truncating variant that abrogates the kinase activity of CHEK2 [6], has been also found to contribute significantly to the familial clustering of breast cancer [7]. The variant has shown a frequency of $1.1 \%$ in healthy individuals and it has been associated with a breast cancer risk ratio of 1.7 in families without $B R C A 1 / 2$ mutations. By contrast, the variant conferred no increased cancer risk in carriers of BRCA $7 / 2$ mutations. The low proportion of familial breast 
cancers attributable to known genes, from $20 \%$ to $25 \%$ [1], reflects major gaps in our knowledge of the genetic background of familial breast cancer.

In addition to the age, sex and genotype specific penetrance, the family history of breast cancer is influenced by demographic factors such as family size and mortality [8]. The aim of the present study was to assess the contribution of the BRCA $/ 2$ mutations and CHEK2 variants to the relative risk of breast cancer for women with affected mothers or sisters. We used the Swedish Family-Cancer (SFC) Database to estimate the distribution of life expectancy, the number of daughters per family and the age specific cumulative risk of female breast cancer in Sweden. The penetrances associated with BRCA1/2 and CHEK2 were taken from the literature. This information was used to simulate the familial clustering of breast cancer under different scenarios.

\section{Patients and methods}

The Swedish Family-Cancer Database was created in mid 1990s by linking census information, death notifications and the administrative family registry at Statistics Sweden to the Swedish Cancer Registry. The Database was updated at the end of 2002 to include more than 10.34 million individuals born in Sweden after 1931 as well as more than 810,000 invasive cancers diagnosed after 1958. The Swedish Cancer Registry is based on separate compulsory notifications of cases from clinicians/pathologists or cytologists and is considered to have completeness close to 100\% [9]. The incidence of cancer in the Database is similar to the incidence in the Cancer Registry $[10,11]$. Data on parity were complete, information on the socioeconomic index and the region was based on population censuses from 1960, 1970, 1980 and 1990. The age of the women in the first generation (mothers) was unrestricted, but the maximum age of women in the second generation (daughters) was 68 years. The present study included 20,742 cases of invasive breast cancer among 3.25 million daughters and 67,575 cases of invasive breast cancer among 2.23 million mothers.

\section{Poisson regression}

The relative risk of breast cancer for daughters $\left(R R_{\text {mother }}\right)$ and sisters $\left(R R_{\text {sister }}\right)$ of Swedish women affected by breast cancer was estimated by Poisson regression. The women in the SFC Database were followed from birth, immigration date or 1961, whichever came latest, until diagnosis of breast cancer, death, emigration date or 31 December 2000. The incidence of breast cancer was explained by the variables: age (5-year bands), period (10-year bands), parity (six groups from 'any parturition' to 'more than five parturitions'), socioeconomic status (six groups), age at first birth (five groups, 5 -year bands between 'before age of $20^{\prime}$ and 'after age of 35') and residential area (four groups). The analyses were carried out for different restrictions of the age at diagnosis of breast cancer, which varied from 50 to 69 years. Computations were performed with the SAS software using the procedure GENMOD.

\section{Simulation}

The SFC Database was used to estimate the cumulative risks of female breast cancer before specific ages. The incidences in BRCA $1 / 2$ mutation carriers reported by Antoniou et al [12] were transformed into cumulative risks by the formula: cumulative risk (\%) = $100 \bullet\left(1-\exp \left[0.05 \cdot \Sigma x_{i}\right]\right)$, where $\Sigma x_{i}$ was the sum of the five-year incidences before the age under consideration. The cumulative risks before the age of 69 years were calculated by linear interpolation. The cumulative risks from the SFC Database, the cumulative risks for $B R C A 1 / 2$ mutation carriers from the literature and the prevalences of BRCA $1 / 2$ mutations found by Loman et al among affected Swedish women [13] were used to estimate the frequency of BRCA $1 / 2$ mutations in Sweden. For example, the cumulative risk of female breast cancer before the age of 40 years of $0.31 \%$, the cumulative risk of breast cancer by the age of 40 years in BRCA 1 mutation carriers of $11.57 \%$ and the prevalence of BRCA 1 mutation carriers in women affected by breast cancer before the age of 40 years of $7.26 \%$, would result in a frequency of BRCA 1 mutations in Sweden of $0.098 \%$. The prevalence and penetrance of CHEK2 variants were based on the study of the CHEK2 Breast Cancer Consortium [7]. The distribution of the number of daughters per family and the distribution of life expectancy were calculated using the SFC Database.

The distribution of family size was used to generate one hundred million nuclear families. The genotypes of the parents were created by using the calculated prevalences of BRCA1/2 mutations and the frequency of CHEK2 variants from the literature. One allele was taken at random from each parent in order to simulate the genotypes of the daughters, under the assumption that women carrying two copies of one mutated genes were nonviable. The individual's age at death was generated by using the distribution of life expectancy 
from the SFC Database. The phenotype of each woman (affected or unaffected) was conditional on her genotype and her age at death. The familial aggregation of breast cancer was explored under different scenarios. The simplest scenario included only one gene; the most elaborated model considered simultaneously BRCAT, BRCA2 and CHEK2. The simulated disease phenotypes were used to calculate the relative risks for daughters and sisters of affected women.

The proportion of familial relative risk attributable to BRCA1, BRCA2 and CHEK2 was assessed by comparing the results from the Poisson regression with the data from the simulation. The formula: $100 \bullet\left(\operatorname{RR}_{\text {BRCA1 } / 2, C H E K 2}-1\right) /\left(\operatorname{RR}_{\text {mother }}-1\right)$ was used to calculate the percentage of maternal excess risk attributable to the three genes, where $\mathrm{RR}_{B R C A 1 / 2, \mathrm{CHEK} 2}$ was the estimated relative risk for daughters of affected women when the simulation included the BRCAT, $B R C A 2$ and CHEK2 genes, and $R_{\text {mother }}$ was the relative risk for daughters of affected women estimated by the Poisson regression based on the SFC Database. Similar calculations were carried out to assess the contribution of BRCA1, BRCA2 and CHEK2 to the relative risk for sisters of affected women.

\section{Results}

The cumulative risks of breast cancer used in the simulation are presented in Table 1. Based on the SFC
Database, $0.003 \%$ of the women had breast cancer by the age of 25 years and $6.48 \%$ of them were affected before the age of 69 years. The penetrances of BRCA1/2 mutations estimated by Antoniou et al [12] are also shown in Table 1. These were $63 \%$ for women who carried BRCA1 mutations and $42 \%$ for BRCA2 mutations carriers by the age of 69 years. The distribution of the number of daughters in the SFC Database was as follows: $68 \%$ of the families had one daughter, $26 \%$ had two daughters, $5 \%$ had three daughters and $1 \%$ of the families had four or more daughters. The calculated distribution of life expectancy is shown in Table $1 ; 77.3 \%$ of the women reached the age of 69 years. The cumulative risks of breast cancer from the SFC Database and previous data from the literature resulted in an estimated prevalence of $B R C A 7$ mutations in Sweden of $0.098 \%$, whereas the estimated prevalence of BRCA2 mutations was $0.052 \%$. Following the study of the CHEK2 Breast Cancer Consortium, $1.1 \%$ of the simulated individuals were CHEK2 mutation carriers [7]. These data were taken into account to generate the phenotype distribution of a large population, which was utilized to compute the familial risk of breast cancer under different scenarios.

The relative risks of breast cancer for women with affected mothers based on the SFC Database are shown in Fig. 1. The RR $\mathrm{mother}_{\text {was }} 2.11(95 \% \mathrm{Cl}$ : 1.85 2.41 ) for breast cancers diagnosed before the age of 50 years, and it decreased to $1.56(95 \% \mathrm{Cl}: 1.46-1.66)$

Table 1. Cumulative risk of breast cancer in Sweden, penetrance of BRCA1 and BRCA2 mutations based on the literature and life expectancy of Swedish women*

\begin{tabular}{|c|c|c|c|c|}
\hline \multirow[b]{2}{*}{ by age } & \multicolumn{3}{|c|}{ Cumulative risk of breast cancer (\%) } & \multirow[t]{2}{*}{$\%$ alive } \\
\hline & all women & BRCA1 mutation carriers & BRCA2 mutation carriers & \\
\hline 25 & 0.003 & 0.10 & 0.10 & 99.1 \\
\hline 30 & 0.02 & 0.65 & 0.70 & 98.8 \\
\hline 35 & 0.09 & 4.26 & 2.47 & 98.4 \\
\hline 40 & 0.31 & 11.57 & 6.20 & 97.7 \\
\hline 45 & 0.85 & 23.59 & 10.37 & 96.5 \\
\hline 50 & 1.74 & 38.31 & 16.18 & 94.3 \\
\hline 55 & 2.95 & 45.96 & 23.05 & 90.5 \\
\hline 60 & 4.26 & 53.51 & 30.55 & 85.9 \\
\hline 65 & 5.59 & 59.38 & 38.61 & 80.5 \\
\hline 69 & 6.48 & 62.73 & 42.25 & 77.3 \\
\hline
\end{tabular}

*[12]; see Patients and methods for details 
for cancers under the age of 65 years. The scenario 'cancer occurs due to CHEK2 mutations' led to estimates of the $R_{\text {mother }}$ practically identical to unity. When only BRCA2 mutations were considered, the estimated $R_{\text {mother }}$ decreased from 1.04 (breast cancers before the age of 50 years) to 1.01 (cancers before the age of 69 years). The scenario 'cancer is attributable BRCA1 mutations' showed the $R_{\text {mother }}$ of 1.43 (cancers diagnosed before the age of 50 years) and the $R R_{\text {mother }}$ of 1.07 (cancers before the age of 69 years). The maternal risks under the scenario 'BRCA1 and BRCA2 mutations' were similar to those after the simultaneous consideration of BRCA 1, BRCA2 and CHEK2 mutations; the $R_{\text {mother }}$ was 1.47 for breast cancer before the age of 50 years and 1.09 for breast cancer before the age of 69 years.

The $\mathrm{RR}_{\text {sister }}$ from the Poisson regression decreased from $2.19(95 \% \mathrm{Cl}: 1.98-2.43)$, for breast cancers diagnosed before the age of 50 years, to 1.97 (95\%Cl: 1.86-2.09), for cancers diagnosed before the age of 60 years (Fig. 2). The scenario 'only BRCA2 mutations' resulted in the $\mathrm{RR}_{\text {sister }}$ of 1.02 (breast cancers diagnosed before the age of 50 years) and the $R R_{\text {sister }}$ of 1.01 (cancers before the age of 69 years). BRCA1 mutations showed the $R_{\text {sister }}$ of 1.41 for breast cancers diagnosed before the age of 50 years, and the $R_{\text {sister }}$ of 1.06 for cancers before the age of 69 years. The results for $B R C A 1$ and $B R C A 2$ mutations were similar to the results for BRCA1, BRCA2 and CHEK2; the $\mathrm{RR}_{\text {sister }}$ was 1.46 for breast cancer diagnosed before the age of 50 years and it was 1.08 for cancers before the age of 69 years.

The excess risk explained by BRCA1, BRCA2 and CHEK2 decreased with increasing ages at diagnosis and it was higher for daughters than for sisters of affected women. For example, 14\% of the relative risk for daughters of women affected by the age of 69 years was related to BRCA1, BRCA2 and CHEK2 mutations, but the corresponding proportion for sisters of affected women was only around $8 \%$.

\section{Discussion}

The most direct way to address the question concerning the existence of other breast cancer susceptibility genes is to ask whether the known genes can explain the observed familial aggregation of breast cancer [1]. Germline mutations in the p53,

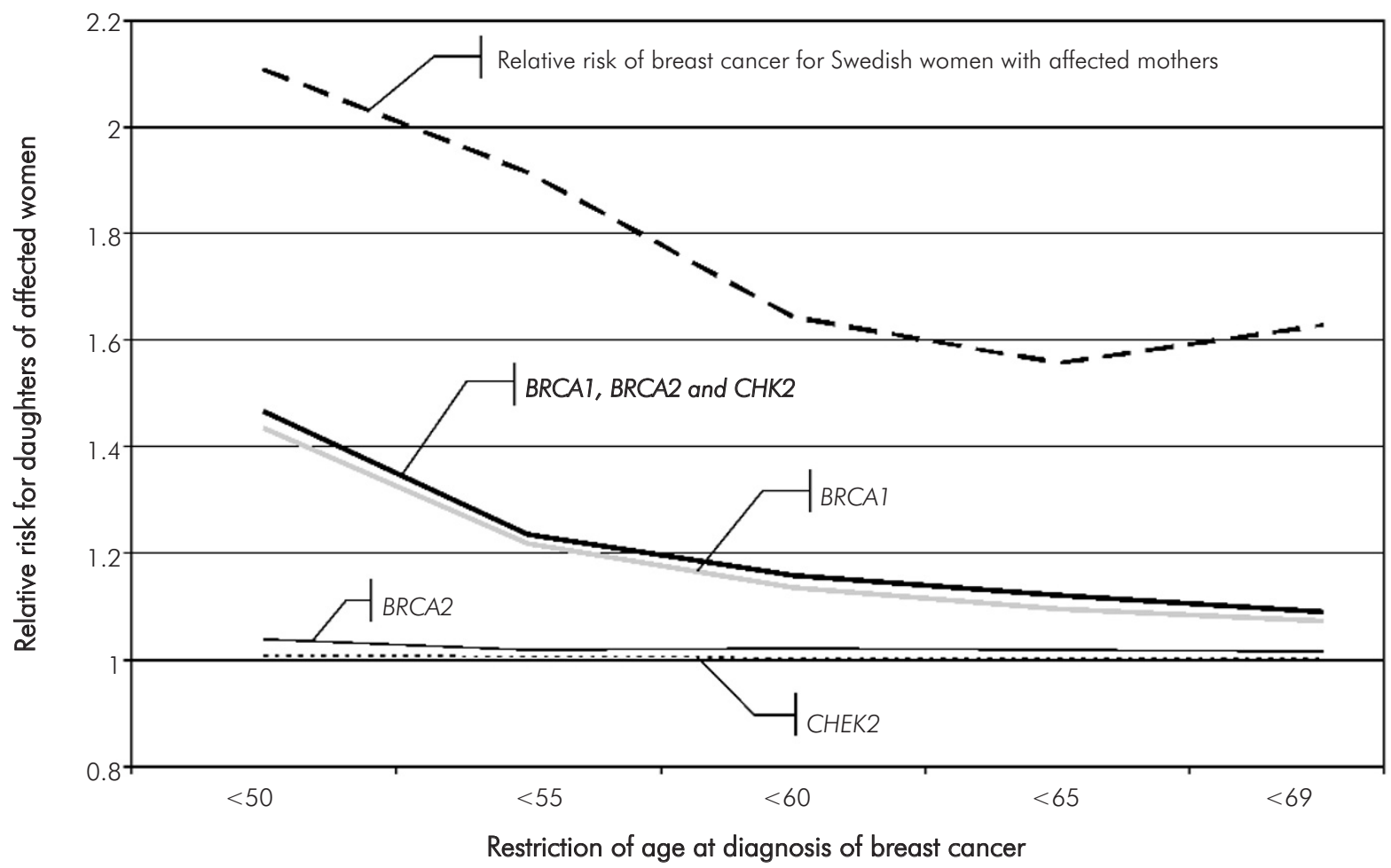

Fig. 1. Relative risk of breast cancer for daughters of women with breast cancer in Sweden and effect of BRCA1, BRCA2 and CHEK2 mutations on the relative risk of breast cancer for daughters of affected women. Both the cases and the probands are restricted to the indicated age 
PTEN, STK $11 /$ LKB 1 and ATM genes are rare in familial breast cancer [14]. The present study assessed the contribution of BRCA1, BRCA2 and CHEK2 to the relative risk of breast cancer. The estimated familial risks for Swedish women relied entirely on registered data of complete coverage. Other important features of this study were the large number of cases analyzed, the standardization for parity and age of first birth, and the inclusion of information on family size and life expectancy in the simulation. The age of the individuals from the first generation in the SFC Database was unrestricted, but the maximum age of the individuals in the second generation (68 years) was a limitation on the present study.

Mutations in BRCA1 and BRCA2 show considerable ethnic and geographic variation [15]. Specific BRCA1 or BRCA2 mutations have become common as a result of founder effects in Ashkenazi Jewish populations [15-17], Poland [18], Iceland [19] and the European part of Russia [20]. The contribution of BRCA1 and BRCA2 to familial breast cancer in those populations is likely to be more important than in Sweden. The mutation prevalences assumed in this study, $0.098 \%$ for BRCA1 and $0.052 \%$ for BRCA2, were calculated using the SFC Database and the Swedish results of Lohman et al [13]. These prevalences are in agreement with the literature, e.g. Easton proposed frequencies between $0.05 \%$ and $0.20 \%$ for both BRCA1 and BRCA2 [1] and Domchek et al estimated a prevalence of BRCA1 mutations of $0.125 \%$ [21]. The prevalence and penetrance assumed for CHEK2 variants may be more inaccurate. This study concentrated on the 1100 delC frameshift mutation and was based on the results from the CHEK2-Breast Cancer Consortium, but the same conclusions were reached by using German [22] or Finish [23] data (results not shown).

The estimated risks were higher for sisters than for daughters of affected women, and the difference between the two familial relative risks increased with the age at diagnosis of breast cancer. Several studies have suggested that this difference is mostly attributable to the unequal number of parturitions and the different calendar year of diagnosis of mothers and sisters [2, $24]$. Since $97 \%$ of the analyzed daughters were parous, the contribution of parity to the difference of relative risks, if any, should be small. In contrast, the median calendar year of diagnosis of mothers was 1971 and that of sisters - 1996. The establishment of screening services in Sweden has resulted in the earlier detection



Fig. 2. Relative risk of breast cancer for sisters of women with breast cancer in Sweden and effect of BRCA1, BRCA2 and CHEK2 mutations on the relative risk of breast cancer for sisters of affected women. Both the cases and the probands are restricted to the indicated age 
of breast cancers [25] and may have also affected the detection of familial cancers.

In contrast to the familial relative risks estimated by the Poisson regression, the relative risks associated with $B R C A 1$ and BRCA2 mutations in the simulation were slightly lower for sisters than for mothers of affected women, especially when the cancers were diagnosed before the age of 50 years. The separate analysis of each gene showed that BRCA1 mutations would explain $34 \%$ to $39 \%$ of the familial relative risk by the age of 50 years, the corresponding figure would be $2 \%$ to $4 \%$ for BRCA2 mutations, and less than $1 \%$ of the familial risk was attributable to CHEK2 variants.

In conclusion, the proportion of excess familial risk due to BRCA1/2 mutations cited in the literature of about 15\% [26], varies considerably with the population and the age at diagnosis of the cancers. In Sweden roughly $40 \%$ of the familial relative risk for breast cancers diagnosed before the age of 50 years is likely to be associated with BRCA1/2 mutations, but around $85 \%$ of the excess risk remains unexplained when all cancers diagnosed before the age of 69 years are considered. The proportion of familial excess attributable to CHEK2 variants, or other low susceptibility genes, is small.

\section{Acknowledgements}

The study was supported by Deutsche Krebshilfe and the Swedish Cancer Society. The Family-Cancer Database was created by linking registers maintained by Statistics Sweden and the Swedish Cancer Registry.

\section{References}

1. Easton DF. How many more breast cancer predisposition genes are there? Breast Cancer Res 1999; 1: 14-17.

2. Pharoah PD, Day NE, Duffy S, Easton DF and Ponder BA. Family history and the risk of breast cancer: a systematic review and meta-analysis. Int J Cancer 1997; 71: 800-809.

3. Lichtenstein P, Holm NV, Verkasalo PK, Iliadou A, Kaprio J, Koskenvuo M, Pukkala E, Skytthe A and Hemminki K. Environmental and heritable factors in the causation of canceranalyses of cohorts of twins from Sweden, Denmark, and Finland. N Engl J Med 2000; 343: 78-85.

4. Ford D, Easton DF, Stratton M, Narod S, Goldgar D, Devilee P, Bishop DT, Weber B, Lenoir G, Chang-Claude J, Sobol H, Teare MD, Struewing J, Arason A, Scherneck S, Peto J, Rebbeck TR, Tonin P, Neuhausen S, Barkardottir R, Eyfjord J, Lynch H, Ponder BA, Gayther SA, Birch JM, Lindblom A, Stoppa-Lyonnet D, Bignon Y, Borg A, Hamann U, Haites N, Scott RJ, Maugard CM, Vasen H, Seitz S, Cannon-Albright LA, Schofield A, ZeladaHedman M and the Breast Cancer Linkage Consortium. Genetic heterogeneity and penetrance analysis of the BRCA1 and BRCA2 genes in breast cancer families. The Breast Cancer Linkage Consortium. Am J Hum Genet 1998; 62: 676-689.

5. Antoniou AC, Pharoah PD, McMullan G, Day NE, Ponder BA and Easton D. Evidence for further breast cancer susceptibility genes in addition to BRCA1 and BRCA2 in a population-based study. Genet Epidemiol 2001; $21: 1-18$.

6. Wu X, Webster SR and Chen J. Characterization of tumorassociated Chk2 mutations. J Biol Chem 2001; 276: 2971 -2974.

7. Meijers-Heijboer H, van den Ouweland A, Klijn J, Wasielewski M, de Snoo A, Oldenburg R, Hollestelle A, Houben M, Crepin $E$, van Veghel-Plandsoen M, Elstrodt F, van Duijn C, Bartels C, Meijers C, Schutte M, McGuffog L, Thompson D, Easton D, Sodha N, Seal S, Barfoot R, Mangion J, Chang-Claude J, Eccles D, Eeles R, Evans DG, Houlston R, Murday V, Narod S, Peretz T, Peto J, Phelan C, Zhang HX, Szabo C, Devilee P, Goldgar D, Futreal PA, Nathanson KL, Weber B, Rahman N and Stratton MR. Low-penetrance susceptibility to breast cancer due to CHEK2 $\left.{ }^{*}\right) 1100$ delC in noncarriers of BRCA1 or BRCA2 mutations. Nat Genet 2002; 31 : 55-59.

8. Sibert A and Goldgar DE. The effect of disease penetrance, family size, and age of onset on family history with application to setting eligibility criteria for genetic testing. Fam Cancer 2003; 2: $35-42$.

9. Cancer incidence in Sweden, 2000. Stockholm, National Board of Health and Welfare 2002; p. 118.

10. Hemminki K, Li X, Plna K, Granstrom C and Vaittinen P. The nation-wide Swedish family-cancer database - updated structure and familial rates. Acta Oncol 2001; 40: 772-777.

11. Plna K and Hemminki K. Familial bladder cancer in the National Swedish Family Cancer Database. J Urol 2001; 166: 2129-2133.

12. Antoniou A, Pharoah PD, Narod S, Risch HA, Eyfjord JE, Hopper $\mathrm{JL}$, Loman N, Olsson H, Johannsson O, Borg A, Pasini B, Radice P, Manoukian S, Eccles DM, Tang N, Olah E, Anton-Culver H, Warner E, Lubinski J, Gronwald J, Gorski B, Tulinius H, Thorlacius S, Eerola H, Nevanlinna H, Syrjakoski K, Kallioniemi OP, Thompson D, Evans C, Peto J, Lalloo F, Evans DG and Easton DF. Average risks of breast and ovarian cancer associated with BRCA1 or BRCA2 mutations detected in case Series unselected for family history: a combined analysis of 22 studies. Am J Hum Genet 2003; 72: $1117-1130$.

13. Loman $\mathrm{N}$, Bladstrom $A$, Johannsson $\mathrm{O}$, Borg $\mathrm{A}$ and $\mathrm{Olsson} \mathrm{H}$. Cancer incidence in relatives of a population-based set of cases of early-onset breast cancer with a known BRCA1 and BRCA2 mutation status. Breast Cancer Res 2003; 5: R175-186.

14. Arver B, Du Q, Chen J, Luo L and Lindblom A. Hereditary breast cancer: a review. Semin Cancer Biol 2000; 10: 271-288.

15. Neuhausen SL. Ethnic differences in cancer risk resulting from genetic variation. Cancer 1999; 86: 2575-2582.

16. Struewing JP, Hartge P, Wacholder S, Baker SM, Berlin M, McAdams M, Timmerman MM, Brody LC and Tucker MA. The risk of cancer associated with specific mutations of BRCA1 and BRCA2 among Ashkenazi Jews. N Engl J Med 1997; 336: $1401-1408$.

17. Tonin P, Ghadirian P, Phelan C, Lenoir GM, Lynch HT, Letendre F, Belanger D, Monte M and Narod SA. A large multisite cancer family is linked to BRCA2. J Med Genet 1995; 32: 982-984.

18. Gorski B, Jakubowska A, Huzarski T, Byrski T, Gronwald J, Grzybowska E, Mackiewicz A, Stawicka M, Bebenek M, Sorokin D, Fiszer-Maliszewska L, Haus $O$, Janiszewska H, Niepsuj S, Gozdz S, Zaremba L, Posmyk M, Pluzanska M, Kilar E, Czudowska D, Wasko B, Miturski R, Kowalczyk JR, Urbanski K, Szwiec M, Koc J, Debniak B, Rozmiarek A, Debniak T, Cybulski C, Kowalska E, Toloczko-Grabarek A, Zajaczek S, Menkiszak J, Medrek K, Masojc B, Mierzejewski M, Narod SA and Lubinski J. A high proportion of founder BRCA1 mutations in Polish breast cancer families. Int J Cancer 2004; 110: 683-686.

19. Thorlacius S, Olafsdottir G, Tryggvadottir L, Neuhausen S, Jonasson JG, Tavtigian SV, Tulinius H, Ogmundsdottir HM and 
Eyfiord JE. A single BRCA2 mutation in male and female breast cancer families from Iceland with varied cancer phenotypes. Nat Genet 1996; 13: 117-119.

20. Loginova AN, Pospekhova NI, Lyubchenko LN, Budilov AV, Zakhar'ev VM, Gar'kavtseva RF, Ginter EK and Karpukhin AV. Spectrum of mutations in BRCA1 gene in hereditary forms of breast and ovarian cancer in Russian families. Bull Exp Biol Med 2003; 136: 276-278

21. Domchek SM, Eisen A, Calzone K, Stopfer J, Blackwood A and Weber BL. Application of breast cancer risk prediction models in clinical practice. J Clin Oncol 2003; 21: 593-601.

22. Dufault MR, Betz B, Wappenschmidt B, Hofmann W, Bandick K, Golla A, Pietschmann A, Nestle-Kramling C, Rhiem K, Huttner C, von Lindern C, Dall P, Kiechle M, Untch M, Jonat W, Meindl A, Scherneck S, Niederacher D, Schmutzler RK and Arnold N. Limited relevance of the CHEK2 gene in hereditary breast cancer. Int J Cancer 2004; 1 10: 320-325.

23. Vahteristo P, Bartkova J, Eerola H, Syriakoski K, Ojala S, Kilpivaara O, Tamminen A, Kononen J, Aittomaki K, Heikkila P, Holli K, Blomqvist C, Bartek J, Kallioniemi OP and Nevanlinna $\mathrm{H}$. A CHEK2 genetic variant contributing to a substantial fraction of familial breast cancer. Am J Hum Genet 2002; 71: 432-438.

24. Easton DF, Matthews FE, Ford D, Swerdlow AJ and Peto J. Cancer mortality in relatives of women with ovarian cancer: the OPCS Study. Office of Population Censuses and Surveys. Int J Cancer 1996; 65: 284-294.

25. Zahl PH, Strand BH and Maehlen J. Incidence of breast cancer in Norway and Sweden during introduction of nationwide screening: prospective cohort study. BMJ 2004; 328: 921-924.

26. Easton DF. Familial risks of breast cancer. Breast Cancer Res 2002; 4: 179-181. 